\title{
EFFICACY ASSESSMENT OF CRYO STORAGE OF DONOR HEARTS BY IMAGEJ BASED IMAGE ANALYSIS
}

\author{
Bao-quan Lin, Sheng-sheng Yang, Zhi-yong Zeng, Cong-wen Zhuang
}

Aim. Donor organ injury during cold preservation before transplantation negatively impacts graft survival. The current study was to examine available evidences for the efficacy of different cold storage solutions that are used to preserve donor hearts in vitro prior to orthotopic transplantation.

Material and methods. A systematic search of full-length articles published from 1980 to August 2012 was performed in PubMed and Google Scholar. Detailed searches were also made for availability of any sourceware for histopathology images of endomyocardial biopsies of stored hearts.

Results. Not even a single controlled trial has been published relating to this topic. However, we assessed all available literature pertaining to this topic, and performed original, simple yet innovative analyses using ImageJ, a Java based image analyses program, to show the tremendous power to objectively examine the efficacy of the storage solution. Our analysis suggest that ImageJ may be conveniently used to obtain evidences (or lack of it) of ischemic injury of donor hearts during cold storage. Conclusions. Even the UNOS database does not provide histopathological evidences of cardiac biopsies of orthotopically transplanted hearts. We, however, make the case of the need for image analyses and making availability of images to allow establishing evidence of the usefulness of these storage solutions. We recommend obtaining endomyocardial biopsy prior to orthotopic transplantation and create a registry of $\mathrm{H} \& \mathrm{E}$ stained slides. This is the only step that will direct us towards evidence based care of such highly critical patients who need the equally challenging surgical intervention of cardiac transplantation.

Russ J Cardiol 2014, 1 (105), Engl.: 45-48

Key words: orthotopic cardiac transplantation, University of Wisconsin solution Celsior, Somah, cardiac storage solution.

Division of Cardiothoracic Surgery, Fuzhou General Hospital of PLA, Fuzhou, China

Corresponding author. Dr. Zhi-yong Zeng, Division of Cardiothoracic Surgery, Fuzhou General Hospital of PLA, No.156, Xierhuan Beilu, Gulou District, Fuzhou 350025, China, Tel: +8659183793137, Fax: +8659122859388, e-mail: zhiyongzeng@126.com

$\mathrm{NIH}-$ National Institutes of Health.

Received December 04, 2013.

Revision received December 06, 2013.

Accepted December 13, 2013.

\section{ОЦЕНКА ЭФФЕКТИВНОСТИ КРИО ХРАНЕНИЯ ДОНОРСКОГО СЕРДЦА С ПОМОЩЬЮ ІМАGЕЈ НА ОСНОВЕ АНАЛИЗА ИЗОБРАЖЕНИЙ}

\author{
Bao-quan Lin, Sheng-sheng Yang, Zhi-yong Zeng, Cong-wen Zhuang
}

\begin{abstract}
Цель. Повреждение донорского органа во время холодного хранения до трансплантации негативно сказывается на приживаемости. В данном исследовании изучаются имеющиеся доказательства эффективности различных растворов для холодного хранения, которые используются для сохранения донорских сердец in vitro до ортотопической трансплантации.

Материал и методы. Систематический поиск полноценных статей, опубликованных с 1980 по август 2012, был выполнен в PubMed и Google Scholar. Детальный поиск также был сделан в любых доступных хранилищах гистопатологических образцов эндомиокардиальных биоптатов сердец.

Результаты. Ни одно контролируемое исследование еще не было опубликовано по этой теме. Тем не менее, мы оценили всю доступную литературу, относящиеся к этой теме, и выполнили оригинальный, простой, но инновационный анализ с использованием ImageJ, Java на основе программы анализа изображения, чтобы показать огромное значение объективной оценки эффективности растворов для хранения. Наш анализ показывает, что ImageJ может быть удобно использован для получения доказательств (или отсутствия таковых) ишемического повреждения донорского сердца во время холодного хранения.
\end{abstract}

\section{Introduction}

Donor organ injury during cold preservation before transplantation negatively impacts graft survival [1]. Most cardiac preservation solutions provide safe cold ischemic storage times for 4 to 5 hours. University of Wisconsin and Celsior are considered gold standards [2, 3]. However, only recently, debates have sprung up regarding the availability of evidences of the efficacy of these solutions in prevention of ischemic injuries of donor hearts [4]. Few newer products like Somah have tried to approach this highly relevant area using rational pharmacological basis for storage. For example, Somah has tried to implement the availability of nitric oxide
Заключение. Даже UNOS база не дает возможность обеспечить гистопатологическими свидетельствами кардиологические биоптаты ортотопически трансплантируемых сердец. Мы, однако, показываем необходимость проведения анализа изображения, чтобы позволить установить доказательства полезности этих растворов для хранения. Мы рекомендуем получение результатов эндомиокардиальный биопсии до ортотопической трансплантации и создание реестра Н\&Е изображений. Это единственный шаг, который направит нас к обоснованной заботе об этих пациентах, находящихся в критическом состоянии, которые нуждаются в столь сложных хирургических вмешательствах по трансплантации сердца.

Российский кардиологический журнал 2014, 1 (105), Англ.: 45-48

Ключевые слова: ортотопическая трансплантации сердца, University of Wisconsin solution, Celsior, Somah, кардиологический раствор для хранения.

donor, which is extremely critical in the cardiac neurovascular bed [5].

Initially, we assessed the freely available transplantation database, the UNOS registry, to understand whether any controlled trial have been performed to assess the relative efficacies of the storage solutions [6]. We searched literature, primarily from PubMed, over the last 20 years and to our surprise, we found only very few (less than 5) studies that have addressed this highly critical area [7-10]. In addition, we found that the UNOS registry has only patients listed between 2004 and current. Furthermore, all the analyses have been entirely based on patient survival and some objective clinical data (ejection fraction, etc) of the efficacy 
of the storage solutions. However, due to unavoidable multivariate interferences, such analyses can never provide insights into the efficacy of the storage solutions.

In the current study, we aimed to obtain image analyses of all available cardiac biopsy materials that have either been published or available from a public database. To our great surprise, we found very few figures that have actually represented the endomyocardial status of the transplanted graft. Clearly, we could not access even a single image of an in vitro stored donor human heart prior to transplantation. However, we, for the first time ever, utilize the freely available image analyses software from the National Institutes of Health (NIH, Bethesda, MD), ImageJ to demonstrate that all aspects of pathophysiology of ischemic donor heart damage after cold storage may be reliably examined by histomorphometry [11]. This is a simple to perform, but will provide us with enormously powered information to objectively assess the efficacy of the storage solutions, and the benefits of any supplements. There are several studies which have reliable demonstrated the power of image analysis in obtaining highly relevant pathophysiological information. We clearly make the case that pending wide spread use of our suggested methodology, we will continue to fall short of providing evidence based care to one of the highest level of critical patients that await or undergo cardiac transplantation.

\section{Material and methods}

Study identification. Detailed systematic PubMed/ Medline and Google Scholar searches were performed using the following (single or combination) $\mathrm{MeSH}$ headings and subheadings and keywords: heart storage solution, University of Wisconsin solution, Celsior, Somah, ATP, nitric oxide, endomyocardial biopsy, comparative, UNOS, ischemia, cardiac ischemic, ischemic reperfusion injury, histopathology, morphometry, image analyses, apoptosis, cardiac injury, troponin, membrane, ploidy, necrosis, ischemic staging. Literature from 1980 till present (August 2012) was reviewed; less than 5 studies were found that have performed controlled trials of comparative assessments of storage solutions, namely University of Wisconsin and Celsior. However, the end point assessments in these studies were patient survival, and clearly, these studies did not provide any information regarding the histopathological status of the donor hearts at various stages including harvesting, short time storage and post-transplantation. Thereafter, we made endeavors to assess whether images of cardiac biopsies are available after storage of the donor hearts for variable periods of time. Here again, we met with very limited success.

Thereafter, we made the original analyses of the efficiency of imaging tools like ImageJ, a java based free program available from the NIH and obtained an image of a cardiac biopsy that was stored in University of Wisconsin solution, and used it to analyze whether different pathophysiological markers of ischemic heart injury may be examined using the image analyses tools available in ImageJ.

Selection criteria. As case series are probably the most widely reported surgical literature, it was decided not to restrict the selection to a specific study design. Betweengroups comparisons in a (randomized) controlled design were not available even for a single study. As a consequence, studies were included if there was within-group pre-post treatment comparisons. No bias was introduced in study selection or methodological screening and all existing reports were analyzed.

Data extraction. ImageJ.Details of ImageJ are easily available from their website, including the different plugins. Those are not discussed here for avoiding repetition and sake of brevity.

Markers of cardiac ischemic injury after storage in different cold storage solutions. Specifically, the feasibility of Image $J$ in assessing the following markers of cardiac injury were made: (A) FOR CARDIAC MUSCLES: (i) integrity of membrane (ii) volume of muscle mass (iii) distance between muscle bundles in cross section to assess edema (iv) nuclear swelling as a marker of cardiac apoptosis (B) FOR BLOOD VESSELS AND ENDOTHELIUM: (i) endothelial swelling (ii) endothelial nuclear integrity (iii) blood vessel diameter (iv) evidence of any intravascular or extravascular inflammatory cellular infiltrate.

\section{Results}

Here in Figure 1, we show that a simple hand tool in Image J may be used to outline a muscle mass that has been obtained in cross section. Further, all parameters may be obtained in one reading, for example, the diameter of the muscle obtained in cross section, the perimeter, area, Feret diameter and the standard deviations of all the measurements. These parameters may be very quickly obtained, and typical analyses for a single area may take less than 10 seconds. For a $512 \times 512$ frame, the whole analyses may be completed in less than 5 minutes, but providing very useful information on overall morphological architecture of the obtained myocardial biopsy tissue. Note that this mensuration can be used to derive several pertinent information regarding the state of the donor heart tissue and the stage of ischemic injury and/or its prevention by the storage solution. For example, the measurement of distance between the muscle masses will clearly define whether there has been any level of edema, a hallmark of early ischemic injuries. Furthermore, the measurement of the muscle mass is an easy indicator of the state of the muscle health and whether it has been affected to any extent by ischemic injury. We stress the tremendous importance of obtaining these baseline values to enable evidence-based care of this highly critical therapeutic area of cardiac transplantation.

In Figure 2, we demonstrate the power of the morphometric analyses by simple tools. Note the outlined blood vessel in yellow on the far left of the image. Such 
diameter measurements of the blood vessels within a myocardial biopsy is a time frozen assessment of the state of endothelium-derived hyperpolarizing factor, and as such, shows the power of image analysis in obtaining the relevant pharmacological efficacy of storage solutions. In absence of nitric oxide, blood vessels may be tonically contracted, providing a poor outlook for the cardiac graft. Surprisingly, we failed to obtain any relevant images that have compared UW, Celsior or any other storage solution, with or without supplementation of nitric oxide donors. We urge that such simple measurements will help us clearly define the efficacy of storage solutions.

In Figure 3, we show the power of "threshold analyses". Morphometrically, the nuclei can be considered as particles. Such an image as shown here is easily obtained digitally, which thereafter can allow us to obtain numerous useful parameters: (i) optical density of the nuclei of muscle cells or endothelial cells; this important parameter is an imaging insight into the metabolic health of whether a nucleus is open faced or condensed and degenerating (ii) clustering of the nuclei; for example, degenerating nuclei of the endothelia will show clustering (iii) simple count of the particles will give an estimate of nuclear densities, for example a useful ratio between muscle and endothelial cells nuclei. An increase in such ratio may be observed if there is an infiltration of inflammatory cells, a hallmark of ischemic injury of transplanted heart. Furthermore, note the clarity of the images; in absence of availability of staining like $\mathrm{CD} 68$, it is still possible to speculate with reasonable confidence if there is a macrophage infiltration, because nuclei of such cells will be clearly visible in an intravascular location during the thresholding process in ImageJ.

In Figure 4, we show that stereological analyses may be obtained very quickly with ImageJ. We can easily overlay obtained biopsy images with grids, and thereafter measure useful parameters like nuclear density, nucleo-cytoplasmic ratios, and volume estimations by useful statistical tools like the Cavalieri. Needless to stress here is the fact that we should have open-access kind of sites where the valuable images be uploaded to be allowed for this kind of detailed, but easily performed image analyses to provide us with relevant information for scientifically understanding the importance of the different storage solutions for donor hearts.

In Figure 5, we show that the edges may be outlined in order to examine the integrity of the membranes of cardiac muscles and blood vessels. For example, edge analyses will allow understanding whether there has been any breach of membrane integrity, and such morphological information may be correlated with any available analyses of troponin assays. Places where highly sensitive troponin assays are unavailable may use such simple measurement tools to make accurate diagnosis of cardiac injury after transplantation.

In Figure 6, we show that optical density of a selected area may be easily obtained pixel by pixel. Such analyses

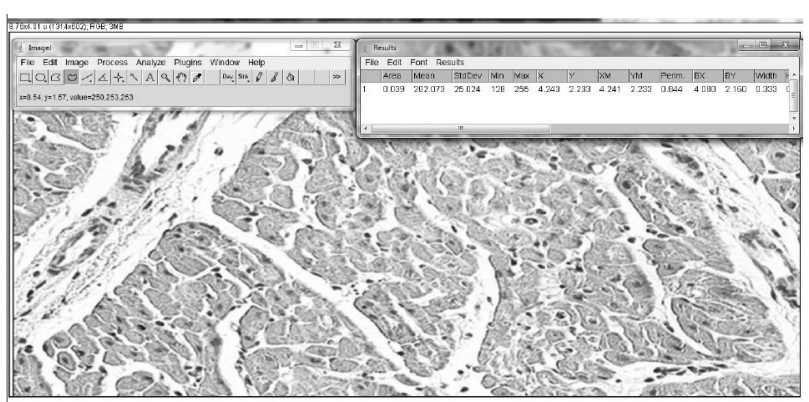

Figure 1. ImageJ used to outline muscle cell boundaries and morphometry obtained. This kind of analyses will provide insights into normal muscle mass and whether any regression or necrosis has occurred.

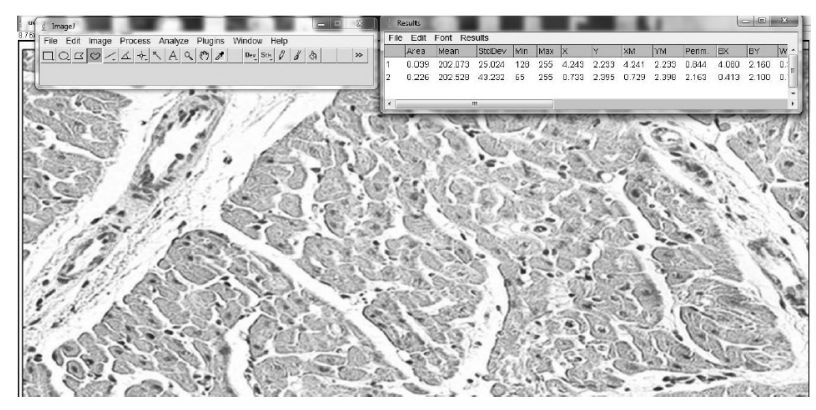

Figure 2. ImageJ can measure diameter of intra-cardiac blood vessels in endomyocardial biopsy obtained after cold storage. This can provide useful insights into the efficacy of storage solutions with supplements like nitroglycerin, nicorandil or Somah.

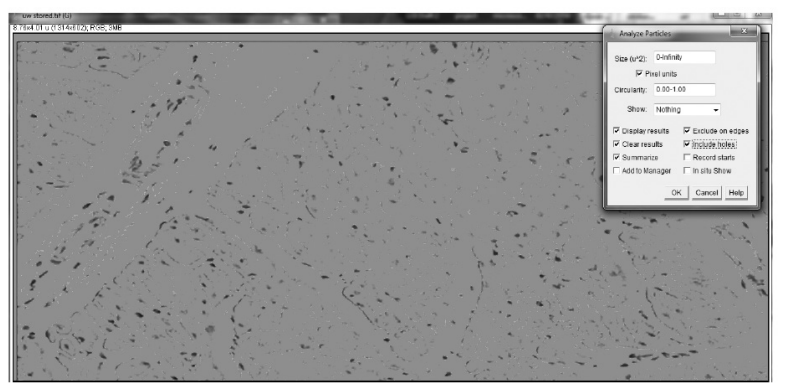

Figure 3. Particle count may be done to assess nuclear cluttering, which may provide further insights into any inflammatory infiltrate.

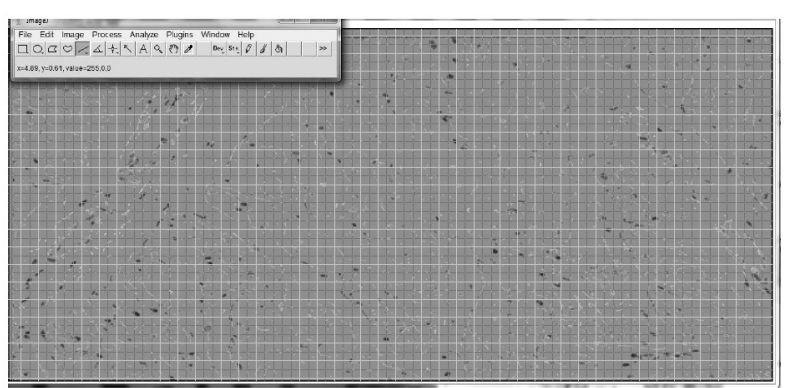

Figure 4. Detailed stereological analyses may be performed with ImageJ. 


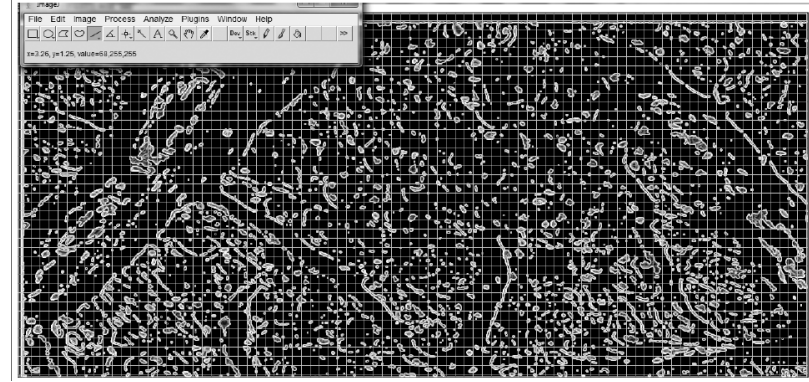

Figure 5. Edge analyses may be performed with ImageJ to examine cell membrane integrity.

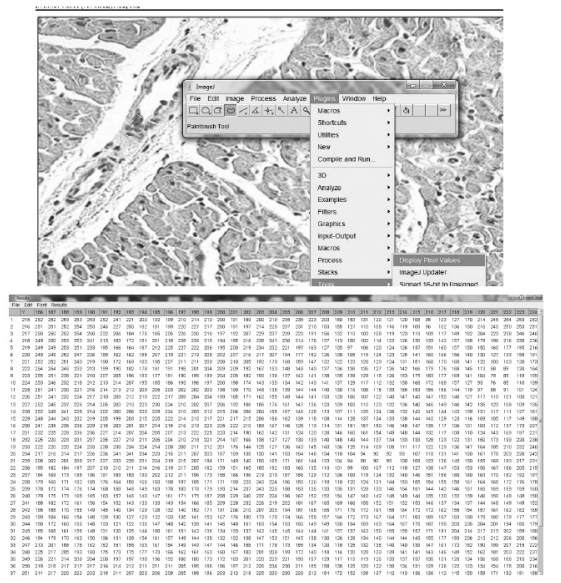

Figure 6. Pixel analysis may be done with ImageJ to obtain insights into nuclear ploidy.

will immediately provide the ploidy status of the endothelial or muscle nuclei.

\section{Discussion}

Here, we demonstrate for the first time ever, the usefulness of simple freely available image analysis tool like the Image $J$ in obtaining highly useful information that can be implemented to objectively assess the efficacy of the different storage solutions for storage of donor organ prior to orthotopic cardiac transplantation. Pioneering work has been done for making cardiac

\section{References}

1. Yetgin $\mathrm{T}$, Manintveld OC, Groen F, et al. The Emerging Application of Remote Ischemic Conditioning in the Clinical Arena. Cardiol Rev 2012; 20: 279-87.

2. Lima ML, Fiorelli Al, Vassallo DV, et al. Comparative experimental study of myocardial protection with crystalloid solutions for heart transplantation. Rev Bras Cir Cardiovasc 2012; 27: 110-6.

3. Poston RS, Gu J, Prastein D, et al. Optimizing donor heart outcome after prolonged storage with endothelial function analysis and continuous perfusion. Ann Thorac Surg 2004; 78: 1362-70.

4. George TJ, Arnaoutakis GJ, Beaty CA, et al. A novel method of measuring cardiac preservation injury demonstrates University of Wisconsin solution is associated with less ischemic necrosis than Celsior in early cardiac allograft biopsy specimens. J Heart Lung Transplant 2012; 31: 410-8.

5. Thatte HS, Rousou L, Hussaini BE, et al. Development and evaluation of a novel solution, Somah, for the procurement and preservation of beating and nonbeating donor hearts for transplantation. Circulation 2009; 120: 1704-13. transplantation a reality for patients suffering from New York Stage IV cardiac failure, as well as a number of different other indications. One important aspect is the storage of the heart after harvesting the donor organ. This is dependent fundamentally on the nature of the cryostorage solution. University of Wisconsin solution and Celsior are commonly used, and a few others like Somah have been introduced that have tried to incorporate rationale use of chemicals for cardiac storage. However, when we scanned the databases, especially the UNOS transplantation database (www.UNOS.org), we surprisingly could not access any useful myocardial biopsy information. We scanned manuscripts published over the last 20 years and again, there were lack of objective assessments of histopathology materials.

No doubt that Kaplan-Meier curve analyses are important aspects in understanding the outcomes of different kind of storage solutions on patient survival. But in the absence of detailed histopathological examinations of any kind of biopsy samples that we can procure, the lacunae in objectivity in the use of these storage solutions is apparent. In the current manuscript, we have demonstrated the immense power of Image J in obtaining all useful information pertaining to ischemic injury after in vitro storage of donor heart with different cryostorants. We have shown that both cardiac muscles and endothelial viability may be examined in details for evidences of ischemic or reperfusion injury.

\section{Conclusion}

In summary, we recommend obtaining endomyocardial biopsy prior to orthotopic transplantation and create a registry of $H \& E$ stained slides. This is the only step that will direct us towards evidence based care of such highly critical patients who need the equally challenging surgical intervention of cardiac transplantation.

\section{Acknowledgements}

We are grateful to Dr. Chi Xu for their help with data collection.
6.

Dardas TF, Cowger J, Koelling TM, et al. The effectiveness of United Network of Organ Sharing status 2 transplantation in the modern era. J Heart Lung Transplant 2011; 30: 1169-74

7. George TJ, Arnaoutakis GJ, Baumgartner WA, et al. Organ storage with University of Wisconsin solution is associated with improved outcomes after orthotopic heart transplantation. J Heart Lung Transplant 2011; 30: 1033-43.

8. Stringham JC, Love RB, Welter D, et al. Does University of Wisconsin solution harm the transplanted heart? J Heart Lung Transplant 1999; 18: 587-96.

9. Kajihara N, Morita S, Tanoue $\mathrm{Y}$, et al. The UW solution has greater potential for longer preservation periods than the Celsior solution: comparative study for ventricular and coronary endothelial function after 24-h heart preservation. Eur J Cardiothorac Surg 2006; 29: 784-9.

10. Baxter $\mathrm{K}$, Howden $\mathrm{BO}$, Jablonski P. Heart preservation with celsior solution improved by the addition of nitroglycerine. Transplantation 2001; 71: 1380-4.

11. Collins T. J. ImageJ for microscopy. Biotechniques 2007; 43: 25-30. 